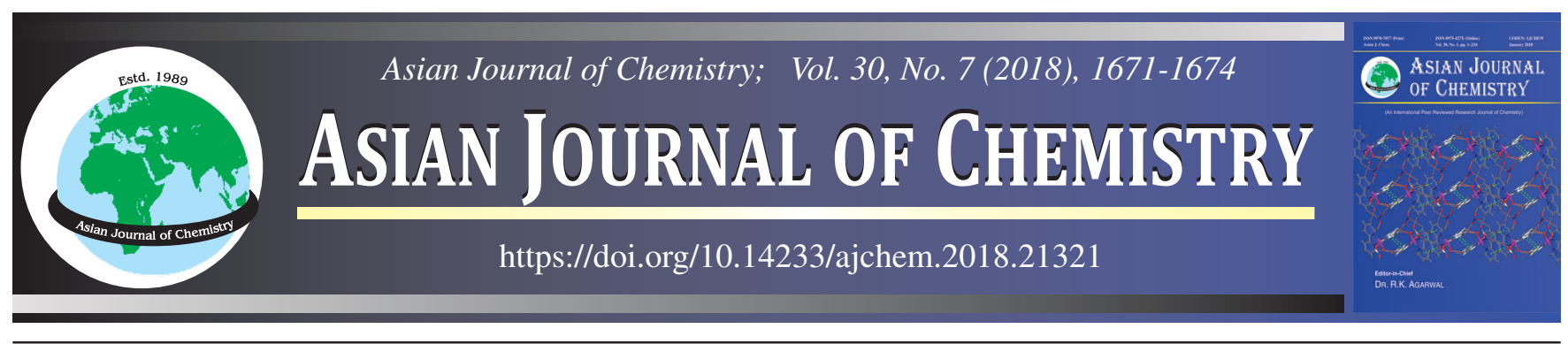

\title{
Effect of Temperature and Calcium Ion Concentration on Gelation and Rheological Properties of Low Methylated Pectin
}

\section{Ajit K. Surabhi ${ }^{1, *}$, Chandra Senan ${ }^{2}$ and Masaud Azhar ${ }^{1}$}

${ }^{1}$ Department of Chemical and Process Engineering Technology, Jubail Industrial College, Jubail Industrial city 31961, Saudi Arabia ${ }^{2}$ Centre for Water Soluble Polymers, Applied Science, Computing \& Engineering, Glyndwr University, Plas Coch, Wrexham, LL11 2AW, Wales, United Kingdom

*Corresponding author: E-mail: ajit_ks@jic.edu.sa

Effect of the influence of temperature and calcium $\left(\mathrm{Ca}^{2+}\right)$ ion concentration on the rheological properties of pectin viz. storage modulus $\left(\mathrm{G}^{\prime}\right)$ and loss $\left(\mathrm{G}^{\prime \prime}\right)$ oscillatory moduli of low methoxyl pectin in the presence of varying amounts of $\mathrm{Ca}^{2+}$ ion. It was observed that upon lowering the temperature in the presence of $\mathrm{Ca}^{2+}$, both $\mathrm{G}^{\prime}$ and $\mathrm{G}^{\prime \prime}$ increased immediately, followed by a further slow logarithmic increase with time. It was also noticed that storage modulus $\left(\mathrm{G}^{\prime}\right)$ increased with rising calcium ion concentration initially but further raising the calcium ion concentration lowered the value of $\mathrm{G}^{\prime}$. The frequency sweep curves revealed that at lower concentrations, pectin- $\mathrm{Ca}^{2+}$ samples exhibited viscoelastic behaviour but at higher concentrations, elastic and well-structured gel-like properties were evident.

Keywords: Rheology, Pectin Gelation, Temperature sweep curve, frequency sweep curve, Storage modulus, Loss modulus.

ᄂ - - - - - - - - - - - - - - - - - - - - - - - - - - - -

\section{INTRODUCTION}

Pectin, a class of complex polysaccharides found and extracted from the cell walls of higher plants, contributes significantly to the texture of fruits and vegetables. Used in many industrial applications, pectin is mainly employed in the food industry as a gelling agent or thickener e.g. in fruit-based preserves such as jams, jellies and marmalade [1-4]. Structurally, it consists of a helical block copolymer of D-galacturonic acid and its methyl ester and it comprises predominantly $\alpha-(1,4)$ linkages between the galacturonic acid residues. Pectins are characterized by their degree of methylation (DM) of carboxyl groups [5,6], solutions of pectin with degree of methylation below $50 \%$ being termed low-methoxyl pectins while high-methoxyl pectins have degree of methylations exceeding $50 \%$ [7]. The gelation mechanism of pectins is mainly governed by their degree of esterification (DE). For low methoxyl pectins (LMP, DE, $50 \%$ ), gelation results from specific, non-covalent ionic interactions between blocks of galacturonic acid residues of pectin backbone and divalent cations such as calcium [8-10]. Pectin gel formation is due to the chelation of calcium ions in regular arrays of electronegative gaps formed by the galacturonic acid residues on the pectin chain structure. Furthermore, the gelation process of pectin occurs in two stages, an initial dimerization process followed by the subsequent aggregation of the preformed dimers $[11,12]$.
Measuring and analyzing the rheological properties of gels can shed light on a product's stability and viscoelasticity which in turn are helpful in monitoring its liquid-like and solid-like behaviour. Dynamic measurements are the most common methods used to obtain information about rheological properties and sample behaviour, viz. storage $\left(\mathrm{G}^{\prime}\right)$ and loss $\left(\mathrm{G}^{\prime \prime}\right)$ moduli. In general, if $\mathrm{G}^{\prime}>\mathrm{G}^{\prime \prime}$, the solutions exhibit elastic properties and gel-like behaviour but when the reverse is the case $\left(\mathrm{G}^{\prime \prime}>\mathrm{G}^{\prime}\right)$ materials display viscous properties [13]. The storage modulus $\left(\mathrm{G}^{\prime}\right)$ of pectin gels increased with decreasing temperature and increasing cation concentrations $[14,15]$.

\section{EXPERIMENTAL}

Oscillatory shear measurements were carried out using an AR 500 Rheometer with a cone geometry (dimensions: 5 $\mathrm{cm}$ radius and $2^{\circ}$ cone angle) in conjunction with a Peltier plate to control the temperature. Rheological experiments were carried out in the presence of varying concentrations of $\mathrm{Ca}^{2+}$ cation. Solutions of the latter were prepared according to the equivalent $(1 \times, 2 \times, 3 \times, 4 \times$ and $5 \times)$ carboxyl $\left[\mathrm{COO}^{-}\right]$concentrations of pectin in distilled water.

Mixtures comprising metal ion solutions of specific concentrations and $1 \%$ pectin were used to conduct all the rheology experiments conducted in this study. The principle object of 
these experiments was to ascertain the effects on the rheology of pectin including quantifying the extent of metal ion binding with pectin by evaluating the storage modulus $\left(\mathrm{G}^{\prime}\right)$ and loss modulus $\left(G^{\prime \prime}\right)$ values. A $1 \%$ pectin solution was prepared by dissolving $1 \mathrm{~g}$ of pectin in $99 \mathrm{~mL}$ of water and heating the solution to maintain a temperature of $70^{\circ} \mathrm{C}$. Metal cation solutions containing $\mathrm{Ca}^{2+}$-equivalent to carboxyl $(\mathrm{COOH})$ concentrations in pectin produced by metal solutions in distilled water were prepared. By utilizing the equivalent carboxyl concentrations in pectin, together with the acid equivalent weights, the cation solution concentrations were calculated.

Pectin solutions $(1 \%)$ and the respective metal cation solutions (of the appropriate concentrations) were maintained at $70^{\circ} \mathrm{C}$. An AR 500 Rheometer was employed to carry out all the oscillation experiments. Once the Peltier plate had attained a temperature of $70{ }^{\circ} \mathrm{C}$, the pectin-cation sample was slowly dispensed onto the plate by means of a syringe, the sample at the periphery being separated by a layer of oil in order to prevent evaporation of the sample. The frequency sweep was then commenced and various rheological parameters $\left(\mathrm{G}^{\prime}, \mathrm{G}^{\prime \prime}, \tan \delta\right.$, dynamic viscosity, etc.) were collated by the TA Advantage software as the experiment progressed. A graph was plotted which illustrate a comparison of the amount (concentration) of bound metal ion (obtained from binding experiments) with the values of storage modulus $\left(\mathrm{G}^{\prime}\right)$ of same amount (concentration) of the identical metal ion, at an oscillatory frequency of $1 \mathrm{~Hz}$ at $25^{\circ} \mathrm{C}$.

\section{RESULTS AND DISCUSSION}

Rheological curves were plotted showing that how $\mathrm{G}^{\prime}$ and $\mathrm{G}^{\prime \prime}$ (storage and loss moduli, respectively) changed as a function of temperature and frequency. Dynamic rheological measurements and analysis of gels facilitated prediction of a product's stability and its viscoelasticity. This enabled their liquid and solid resembling behaviour to be monitored. Hence rheological studies have many applications in the food and polymer processing industries.

The temperature and metal ion concentration dependence of storage $\left(\mathrm{G}^{\prime}\right)$ and loss $\left(\mathrm{G}^{\prime \prime}\right)$ moduli of the pectin solutions in the presence of $\mathrm{Ca}^{2+}$ ion for a temperature sweep curve on cooling from $70^{\circ} \mathrm{C}$ to $25^{\circ} \mathrm{C}$ are shown in Figs. 1 and 2, respectively. From these results, it can be observed that dynamic modulus was increasing with decreasing temperature for all the samples while gel strength increases with ionic strength of the polymer solution $[4,12]$. Additionally, at lower ionic concentrations, both $G^{\prime}$ and $G^{\prime \prime}$ were almost similar, the difference between storage ( $\mathrm{G}^{\prime}$-elastic) and loss $\left(\mathrm{G}^{\prime \prime}\right.$-viscous) moduli increasing with rising ionic strength. Thus, pectin solutions exhibited elastic properties akin to that of a proper gel. In contrast, at lower ionic concentrations, viscous behavior was displayed owing to the fact that there is insignificant difference between $\mathrm{G}^{\prime}$ and $\mathrm{G}^{\prime \prime}$, with $\mathrm{G}^{\prime \prime}$ being occasionally higher than $\mathrm{G}^{\prime}$. The gelation process is strongly affected by the initial composition and structural organization of pectin, as well as the concentration of the metal ions present [13]. At higher temperatures, while cooling the cation $\left(\mathrm{Ca}^{2+}\right)$ augmented pectin, the solution displayed liquid-like behaviour. Conversely, on decreasing the temperature, a transition from the solution state

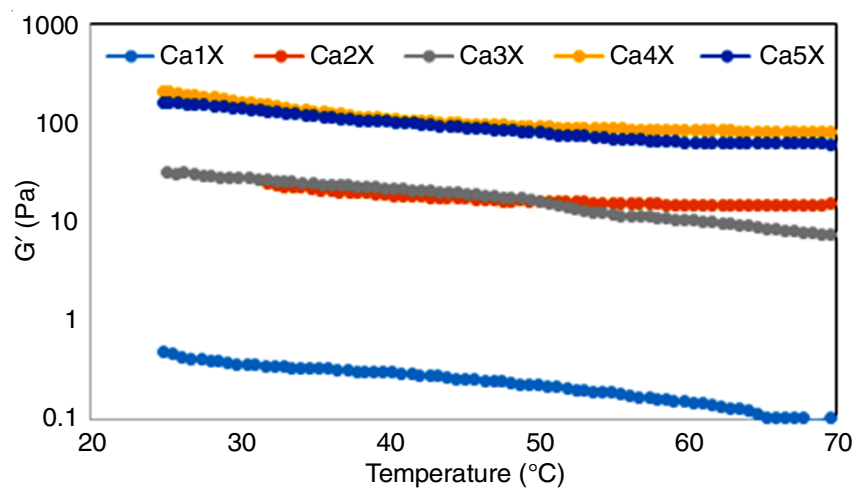

Fig. 1. Pectin-Ca ${ }^{2+}$ temperature sweep curves for storage modulus $\left(\mathrm{G}^{\prime}\right)$ with $\mathrm{LMH}$ pectin

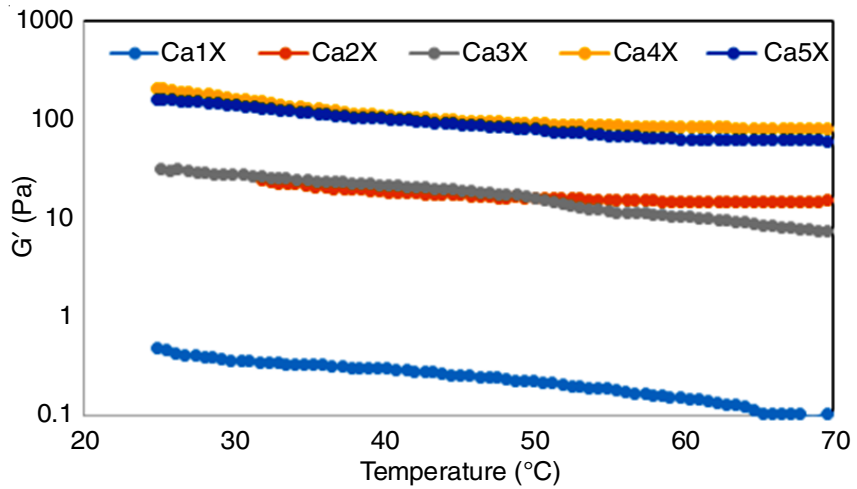

Fig. 2. Pectin- $\mathrm{Ca}^{2+}$ temperature sweep curves for loss modulus $\left(\mathrm{G}^{\prime \prime}\right)$ with LMH pectin

to a gel-like association was observed.Thegelling mechanism involved in the pectin- $\mathrm{Ca}^{2+}$ system was attributed to the formation of two distinct types junction zones, mediated by the stoichiometric ratio of cation to anion viz. $\mathrm{M}^{2+} / \mathrm{COO}^{-}$. A short, egg-box type of cooperative helix junction zones would be followed by an aggregation process upon cooling $[12,16]$.

From the temperature sweep curves, cation $\mathrm{Ca}^{2+}$ developed a consistent gel with pectin. The gel showed no breakage at lower temperatures and despite the storage modulus (at lower concentrations) being minimal, as the cation concentration increased, the storage modulus rose to reach a maximum value. However, at higher temperatures, the storage modulus was found to be extremely low and a consistent gel was not formed. The final results of the rheological studies are in good agreement with those of Clark et al. [14,15], who investigated the dependency of the shear modulus of pectins (with a low degree of esterification, $\Delta \mathrm{E}$ ) on calcium ion concentrations and temperature. However, in the current study, we did not evaluate the effect of pectin concentration on cation-pectin gels.

The variation of storage and loss moduli of materials with oscillatory frequency are often termed their mechanical spectra. Both the frequency dependence and metal ion concentration dependence of storage $\left(G^{\prime}\right)$ and loss $\left(G^{\prime \prime}\right)$ moduli of the pectin solutions (in the presence of $\mathrm{Ca}^{2+}$ ions) for generation of a frequency sweep curve are shown in Figs. 3 and 4, respectively.

In the frequency domain, it was observed -- by means of oscillatory experiments -- that $\mathrm{G}^{\prime}$ and $\mathrm{G}^{\prime \prime}$ were frequency dependent and decreased with diminishing frequency. As the frequency increased (which depended on $\mathrm{Ca}^{2+}$ concentration) 


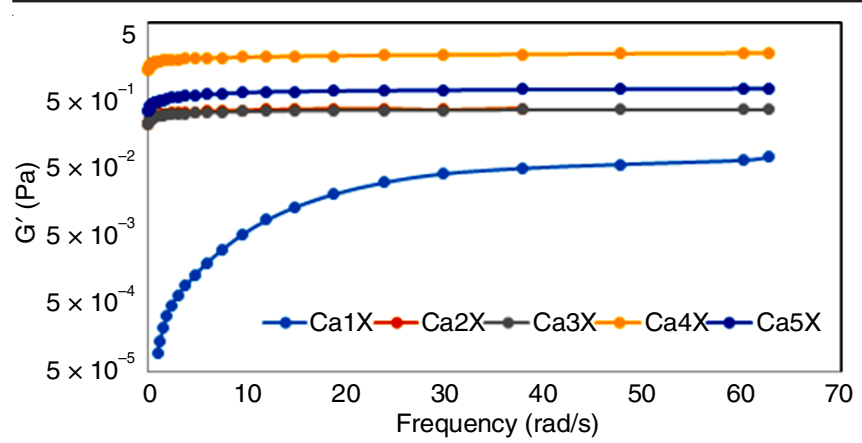

Fig. 3. Pectin- $\mathrm{Ca}^{2+}$ frequency sweep curves depicting variation of storage modulus $\left(\mathrm{G}^{\prime}\right)$ with frequency for LMH pectin

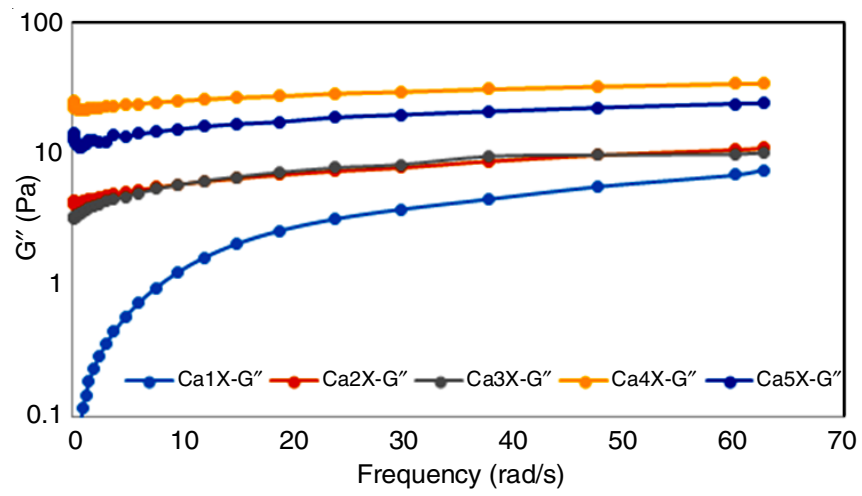

Fig. 4. Pectin-Ca ${ }^{2+}$ frequency sweep curves depicting variation of loss modulus $\left(\mathrm{G}^{\prime \prime}\right)$ with frequency for $\mathrm{LMH}$ pectin

a rapid rise of the storage $\left(\mathrm{G}^{\prime}\right)$ and loss $\left(\mathrm{G}^{\prime \prime}\right)$ moduli followed by a much weaker frequency dependence at higher frequencies was noted.

Dynamic moduli $\left(\mathrm{G}^{\prime}\right.$ and $\left.\mathrm{G}^{\prime \prime}\right)$ and gel strength are also cation concentration dependent in pectin solutions. The storage modulus and gel strength are essentially having similar properties and, being proportional to each other. Both these attributes increase with increasing ionic strength of the polymer solution, for both the ions investigated in this study. This increase was observed until $3 \times \mathrm{COO}$ equivalent concentrations for $\mathrm{Ca}^{2+}$-pectin solution was reached. However, a subsequent reduction in $\mathrm{G}^{\prime}$ and $\mathrm{G}^{\prime \prime}$ was noticed, signaling decreasing cation dependence. Although $\mathrm{G}^{\prime}$ and $\mathrm{G}^{\prime \prime}$ both increased with rising ion concentrations, because $G^{\prime}$ was higher than $G^{\prime \prime}$, the samples predominantly exhibited elastic behaviour (reflected by their gellike properties.) The samples also displayed increasing gel strength with ionic concentration.

$\mathrm{G}^{\prime}$ and $\mathrm{G}^{\prime \prime}$ both increased with decreasing temperatures as indicated by the temperature sweep curves, and both moduli increased at higher frequencies (as shown by the frequency sweep curves). It was noted that the storage modulus was higher than the loss modulus, except at $1 \times \mathrm{Ca}^{2+}$ concentration when the sample was displaying viscous behaviour since the storage modulus $\left(\mathrm{G}^{\prime}\right)$ was slightly lower than the loss modulus $\left(\mathrm{G}^{\prime \prime}\right)$. Moreover, $\mathrm{G}^{\prime}$ was observed to increase as $\mathrm{Ca}^{2+}$ concentration was raised, reaching a maximum $G^{\prime}$ value before decreasing. Thus, pectin- $\mathrm{Ca}^{2+}$ samples were exhibiting viscous behaviour at lower $\mathrm{Ca}^{2+}$ concentrations and good elastic behaviour at higher $\mathrm{Ca}^{2+}$ concentrations. These results are consistent with the results of Lootens et al. [4], who investigated the influence of calcium ion concentration and temperature on storage and loss moduli of low methylated pectin solutions. The aforementioned researchers had concluded that shear moduli of pectin solutions containing $\mathrm{Ca}^{2+}$ ions will increase with decreasing temperature and that $\mathrm{G}^{\prime}$ increased with increasing $\mathrm{Ca}^{2+}$ ion concentration.

The frequency sweep curves illustrate that storage $\left(\mathrm{G}^{\prime}\right)$ and loss $\left(\mathrm{G}^{\prime \prime}\right)$ moduli of pectin solutions (in the presence of various concentrations of $\mathrm{Ca}^{2+}$ ions) had been measured with the application of increasing frequency on the sample. The frequency sweep curves of pectin- $\mathrm{Ca}^{2+}$ samples, suggested that both $G^{\prime}$ and $G^{\prime \prime}$ increased with increasing frequencies, the storage moduli being higher than the loss moduli for all the concentrations studied, except for the $1 \times \mathrm{Ca}^{2+}$ concentration. At this particular concentration, the sample showed viscous behaviour at lower frequencies because the storage modulus $\left(G^{\prime}\right)$ was marginally lower than the loss modulus $\left(G^{\prime \prime}\right)$. However, as frequency progressively increased, the $G^{\prime}$ and $G^{\prime \prime}$ values were almost equal in magnitude, as the sample began to display viscoelastic attributes.

Hence, pectin- $\mathrm{Ca}^{2+}$ solutions are exhibiting viscous behaviour at lower concentrations but display elastic and well-structured gel characteristics at higher concentrations, as gleaned from the frequency sweep curves. These results are in agreement with those of Khondkar et al. [17] and Rao \& Cooley [18], who worked on the cross-linked and uncross linked gelation of maize starch with pectin gels. They found that the samples registered quite high storage moduli, thereby confirming that they possessed the greatest degree of elasticity and were very well structured. According to Kyomugasho et al. [19] increasing cation concentration in cation-mediated pectin gels gives rise to gels comprising a more intertwined network. This implies increased gel stiffness, up to a certain extent, beyond which a drop in $\mathrm{G}^{\prime}$ is observed.

Similar behaviour was indicated by the rheological results, it being evident that with increasing $\mathrm{Ca}^{2+}$ concentration, the storage modulus increased by up to four times its equivalent concentration. This was followed by a reduction in storage modulus. Thus gel stiffness increased up to a certain point, after which it fell, corroborating the assertion that the cation plays a role in determining the properties of the gel.

Fig. 5 illustrates the change in $\mathrm{G}^{\prime}$ with variation in the ratio of $\mathrm{Ca}^{2+}$ concentrations to equivalent carboxylic $\left(\mathrm{COO}^{-}\right)$ ion concentrations. The $\mathrm{G}^{\prime}$ values were obtained from the individual frequency sweep curves, at the point where $\mathrm{G}^{\prime}$ corresponds to a frequency of $1 \mathrm{rad} / \mathrm{s}$. The storage moduli $\left(\mathrm{G}^{\prime}\right)$ of the pectin solutions produced as a function of different $\mathrm{Ca}^{2+}$ ions equivalent concentrations are shown in the graph. The $\mathrm{G}^{\prime}$ values were seen to increase up to $4 \times \mathrm{Ca}^{2+}$ ion equivalent concentration, reaching a maximum of $200 \mathrm{~Pa}$ before decreasing.

It was observed that gel strength increases when the ionic strength of the solvent is raised, until a certain concentration of the ions is attained. Most of the pectin- $\mathrm{Ca}^{2+}$ samples display elastic properties rather than viscous behaviour, reflected by the fact that the storage modulus is higher than the loss modulus. The origin of storage modulus coincides with the formation of crosslinks by complexation of $\mathrm{Ca}^{2+}$ cation with the carboxylic ion $\left(\mathrm{COO}^{-}\right)$containingpectin segments. However, at higher concentrations of cation, the value of $\mathrm{G}^{\prime}$ decreases. This could 


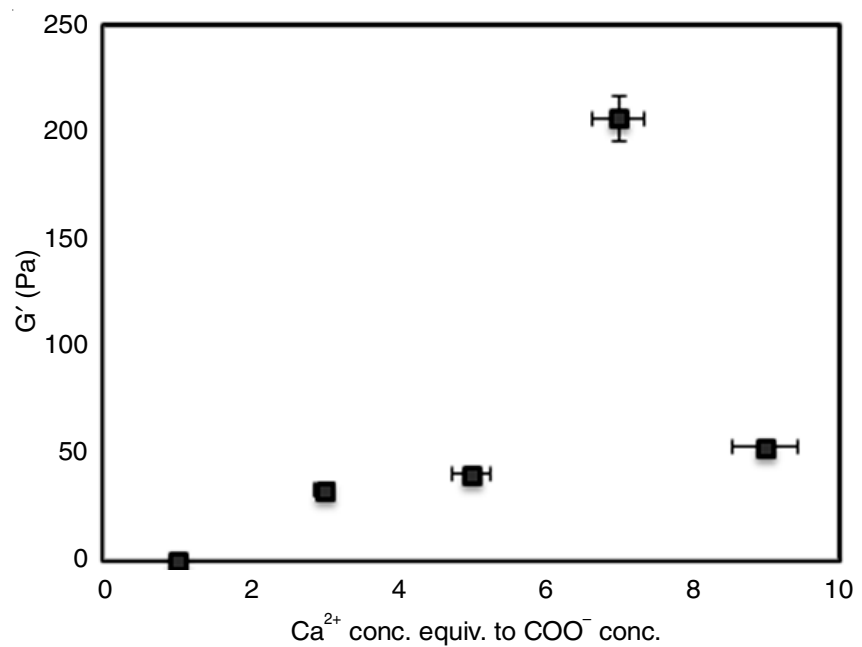

Fig. 5. Storage modulus $\left(\mathrm{G}^{\prime}\right.$ corresponds to frequency of $1 \mathrm{rad} / \mathrm{s}$ in frequency sweep curves) curve for $\mathrm{Ca}^{2+}$ with using $\mathrm{LMH}$ pectin

be attributed to the pectin-cation forming a complex molecule rather than a gel, evidence of which has been reported by Siew et al. [16]. These results correlate well with the findings of Clark et al. [15] who elucidated the effects of temperature and concentration on the gelation of pectin.

On cooling, both the storage and loss moduli were seen to increase as the temperature decreased. This behaviour was anticipated, given the results Lootens et al. [4] had generated in their investigation of the influence of calcium ion concentration and $\mathrm{pH}$ on storage and loss moduli. They found that upon lowering the temperature of low methylated pectin solutions, the ensuing cooling in the presence of $\mathrm{Ca}^{2+}$ ions caused both $\mathrm{G}^{\prime}$ and $\mathrm{G}^{\prime \prime}$ to increase sharply immediately and subsequently to exhibit a slow logarithmic increase. The storage modulus $\left(\mathrm{G}^{\prime}\right)$ of pectin- $\mathrm{Ca}^{2+}$ was observed to increase with rising $\mathrm{Ca}^{2+}$ ion concentrations, eventually reaching a maximum value. This is consistent with Gigli et al. [12] who studied the rheological behaviour of low-methylated pectin gels over an extended frequency window. These researchers found that the gel strength and storage modulus both increased for all $\mathrm{Ca}^{2+}$ ion concentrations they had monitored.

\section{Conclusion}

From the rheological studies, it is evident that the storage modulus $\left(\mathrm{G}^{\prime}\right)$ increased (to a certain level) with cooling and also with rising metal ion concentrations. A further increase of cation concentration caused the storage modulus to drop off sharply. At lower temperatures, storage modulus values were high, owing to the fact that at reduced temperatures, gelation was favourable, with the sample showing good elastic behaviour. In contrast, at higher temperatures, the storage modulus recorded were low, a consequence of the fact that the temperature remarkably affects gel formation. Frequency sweep results indicated that the storage moduli were higher than the loss modulus. Thus the system can be described as being wellstructured (at higher concentrations of metal ion) when the particles are strongly associated. It can be concluded that gel formation is very sensitive to both ionic strength of the solution and to the prevailing temperature. The viscoelastic properties of the gel were observed to be remarkably affected by cation concentrations. Additionally, gel strength was found to increase with decreasing temperature and increasing cation concentration, rising to a maximum value of gel strength before decreasing.

\section{REFERENCES}

1. R.H. Walter and H.L. Matias, Food Hydrocoll., 3, 205 (1989); https://doi.org/10.1016/S0268-005X(89)80004-9.

2. C.D. May, Carbohydr. Polym., 12, 79 (1990); https://doi.org/10.1016/0144-8617(90)90105-2.

3. C. Rolin, in eds.: R. Whistler and J. BeMiller, Pectin, In: Industrial Gums: Polysaccharides and Their Derivatives, Academic Press, edn 3, pp. 257-293 (1993).

4. D. Lootens, F. Capel, D. Durand, T. Nicolai, P. Boulenguer and V. Langendorff, Food Hydrocoll., 17, 237 (2003); https://doi.org/10.1016/S0268-005X(02)00056-5.

5. D.G. Oakenfull and A. Scott, J. Food Sci., 49, 1093 (1984); https://doi.org/10.1111/j.1365-2621.1984.tb10401.x.

6. B.R. Thakur, R.K. Singh, A.K. Handa and M.A. Rao, Crit. Rev. Food Sci. Nutr., 37, 47 (1997); https://doi.org/10.1080/10408399709527767.

7. A.G.J. Voragen, H.A. Schols and R.G.F. Visser, Advances in Pectin and Pectinase Research, Dordrecht, Germany (2003).

8. S.M. Cardoso, M.A. Coimbra and J.A. Lopes da Silva, Food Hydrocoll., 17, 801 (2003); https://doi.org/10.1016/S0268-005X(03)00101-2.

9. C. Garnier, M.A.V. Axelos and J.F. Thibault, Carbohydr. Res., 256, 71 (1994); https://doi.org/10.1016/0008-6215(94)84228-0.

10. R. Kohn, Carbohydr. Res., 160, 343 (1987); https://doi.org/10.1016/0008-6215(87)80322-1.

11. D. Durand, C. Bertrand, J.P. Busnel, J.R. Emery, M.A.V. Axelos and J.F. Thibault, Physical Networks-Polymers and Gels, p. 283 (1990).

12. J. Gigli, C. Garnier and L. Piazza, Food Hydrocoll., 23, 1406 (2009); https://doi.org/10.1016/j.foodhyd.2008.09.015.

13. J. Mierczynska, J. Cybulska, B. Solowiej and A. Zdunek, Carbohyd. Polym., 133, 547 (2015); https://doi.org/10.1016/j.carbpol.2015.07.046.

14. A.H. Clark and D.B. Farrer, Food Hydrocoll., 10, 31 (1996); https://doi.org/10.1016/S0268-005X(96)80051-8.

15. A.H. Clark, K.T. Evans and D.B. Farrer, Int. J. Biol. Macromol., 16, 125 (1994); https://doi.org/10.1016/0141-8130(94)90038-8.

16. C.K. Siew, P.A. Williams and N.W.G. Young, Biomacromolecules, 6 , 963 (2005); https://doi.org/10.1021/bm0493411.

17. D. Khondkar, R.F. Tester, N. Hudson, J. Karkalas and J. Morrow, Food Hydrocoll., 21, 1296 (2007); https://doi.org/10.1016/j.foodhyd.2006.10.008.

18. M.A. Rao and H.J. Cooley, J. Food Sci., 58, 876 (1993); https://doi.org/10.1111/j.1365-2621.1993.tb09381.x.

19. C. Kyomugasho, S. Christiaens, D. Van de Walle, A.M. Van Loey, K. Dewettinck and M.E. Hendrickx, Food Hydrocoll., 61, 172 (2016); https://doi.org/10.1016/j.foodhyd.2016.05.018. 